\title{
STRUKTUR KOMUNITAS MOLUSKA DI VEGETASI MANGROVE DESA KULU, KECAMATAN WORI, KABUPATEN MINAHASA UTARA
}

\section{(Commonity Structure of Mollusc in Mangrove Vegetation of Kulu Village, Wori, North Minahasa Regency)}

\author{
Arnol R. Rau ${ }^{1^{\star}}$, Janny D. Kusen ${ }^{1}$, Carolus P. Paruntu ${ }^{1}$. \\ ${ }^{1}$ Program Studi IImu Kelautan, Fakultas Perikanan dan IImu Kelautan, Universitas Sam \\ Ratulangi, Manado \\ "e-mail :arnold_rau@yahoo.com
}

There are aquatic living organisms in the mangrove area that has been associated with mangrove vegetation such as molluscs, crustaceans, as well as fishes. The molluscs are very plenty find in mangrove area in Indonesia. Some of those molluscs species are living in the roots, wherever others occupying the mangrove stems, such as species from family Ellobidae and family Pottamidae. The purpose of this research were to identified the mollusks that has been associated with mangrove vegetation; to described the community structure through analyzed of diversity index, species richness, density, frequency, dominance, and Important Value Index. The method that have been used in this research was quadrant method. Five quadrants sized $1 \times 1 \mathrm{~m}$ were settled at each station, and all mollusks specimens that found inside the quadrant were collected ant put on labeled container. There were 11 species from 8 families found at the study sites, such as Littoraria scabra, Nerita planospira, Chicoreus capucinus, Nerita undata, Chrithidea cingulata, Terebralia sulcata, Telecopiun telescopium, Polymesoda expansa, Isognomon ephippium, Saccostrea cucculata, Anomalocardia squamosa. The diversity index result was 1,060 , richness index 2,387 , density $0,660 \mathrm{ind} / \mathrm{m}$, frequency of occurrence that varies between 0.067 to 0.667 , dominance index value of 0.152 . The highest importance value index was Littoraria scabra 75.67 whereas the lowest were 3 species, Polymesoda expansa, Saccostrea cucculata and Anomalocardia squamous with index value of 3.54 , repectively.

Keywords : Community, Mollusca, mangrove, North Minahasa.

Di daerah mangrove terdapat biota akuatik yang hidup berasosiasi dengan mangrove antara lain moluska, krustasea dan ikan. Moluska sangat banyak ditemukan pada daerah mangrove di Indonesia. Jenis-jenis moluska ini ada yang menempati akar dan ada juga yang mendiami batang mangrove antara lain famili Littorinidae dan yang menempati daerah lumpur di dasar akar antara lain famili Ellobiidae dan Pottamidae. Tujuan dari pernelitian ini yaitu untuk mengidenifikasi moluska yang berasosiasi dengan vegetasi mangrove; mendeskripsikan struktur komunitas melalui analisa nilai indeks keanekaragaman, kekayaan jenis, kepadatan, frekuensi, dominasi dan indeks nilai penting. Metode yang digunakan yakni, metode kuadran, dengan cara meletakan lima buah kuadran $1 \times 1$ meter pada masing-masing stasiun. Terdapat 11 spesies dari 8 famili yaitu, Littoraria scabra, Nerita planospira, Chicoreus capucinus, Nerita undata, Chrithidea cingulata, Terebralia sulcata, Telecopiun telescopium, Polymesoda expansa, Isognomon ephippium, Saccostrea cucculata, Anomalocardia squamosa. Nilai indeks keanekaragaman yaitu 2,060, nilai indeks kekayaan yakni 2,387, kepadatan $0,660 \mathrm{ind} / \mathrm{m}^{2}$, frekuensi kemunculan bervariasi antara 0,067-0,667, nilai indeks dominasi yakni 0,152 dan indeks nilai penting tertinggi yakni Littoraria scabra 75,67 dan terendah terdapat 3 spesies yakni Polymesoda expansa, Saccostrea cucculata dan Anomalocardia squamosa dengan nilai indeks 3,54.

Kata kunci : komunitas, moluska, mangrove, Minahasa Utara. 


\section{PENDAHULUAN}

Mangrove merupakan komunitas laut dangkal yang menarik dan khas dari perairan tropis maupun sub-tropis serta memiliki manfaat yang penting bagi kepentingan sosial ekonomi masyarakat di sekitarnya juga sebagai devisa negara. Mangrove biasanya tumbuh meluas dan tahan terhadap salinitas laut terbuka. Zonasi sepanjang pantai tidak hanya penting untuk memperluas pantai dan membentuk pulau, tetapi juga melindungi pantai dari pengikisan secara dahsyat yang ditimbulkan oleh badai tropis yang hebat (Odum 1993). Pada wilayah ini terdapat beberapa ekosistem yang unik dan saling terkait, dinamis dan produktif. Secara ekologi mangrove juga memiliki fungsi yakni sebagai daerah asuhan, mencari makan dan pemijahan bagi biota khususnya moluska, krustasea dan ikan yang berasosiasi dengan mangrove (Bengen, 2002). Moluska sangat banyak ditemukan pada daerah mangrove di Indonesia (Noor dkk. 2006). Desa Kulu merupakan salah satu desa di Kecamatan Wori Kabupaten Minahasa Utara yang saat ini masih memiliki vegetasi mangrove dalam kondisi baik. Vegetasi mangrove di pesisir pantai Desa Kulu juga mempunyai biotabiota akuatik yang beraneka ragam. Biotabiota tersebut memiliki interaksi bioekologi dengan keberadaan hutan mangrove, karena diketahui hutan mangrove merupakan habitat yang ekstrim dan setiap hari terjadi dua kali pasang dan surut, sehingga selalu terjadi perubahan parameter fisika, kimia eksternal. Dengan demikian maka perlu dilakukan penelitian mengenai keberadaan dan status ekologi biota akuatik khususnya moluska, yang berasosiasi dengan mangrove. Penelitian ini bertujuan untuk mengidentifikasi dan mendeskripsikan struktur komunitas dengan cara menghitung nilai indeks keanekaragaman, kekayaan, kepadatan, frekuensi, dominasi dan indeks nilai penting

\section{METODE PENELITIAN}

Penelitian dilaksanakan di pesisir Desa Kulu, Kecamatan Wori, Kabupaten Minahasa Utara, Provinsi Sulawesi Utara. Pengambilan data dilakukan pada tiga stasiun penelitian di lokasi tersebut. Sampel dalam penelitian ini diperoleh dengan cara meletakan lima buah kuadran 1 × 1 meter pada masing-masing stasiun. Jarak antar stasiun masing-masing 100 m (Gambar 1)

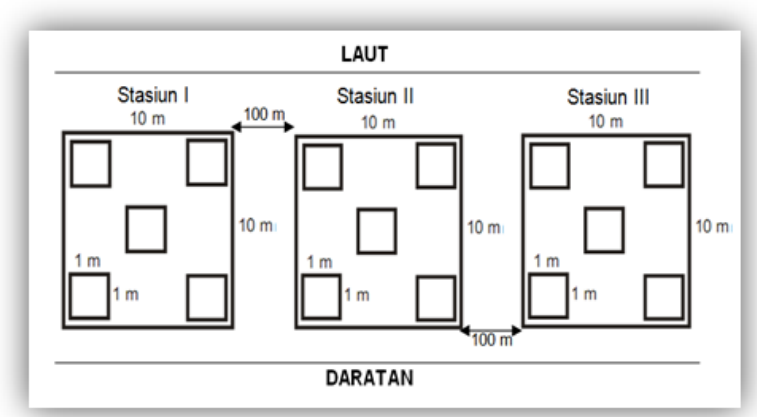

Gambar 1. Tata letak dan ukuran kuadran.

Pengumpulan spesimen dilakukan pada siang hari pada saat air surut. Spesimen yang terdapat dalam kuadran tersebut diambil kemudian dimasukan kedalam kantong yang telah diberi label, selanjutnya diawetkan dan dibawa ke laboratorium Biologi Kelautan FPIK UNSRAT untuk diidentifikasi dan dianalisis. Identifikasi menggunakan buku petunjuk antara lain Dharma (1988, 2005). Analisa data mengikuti beberapa formula berikut ini :

$$
\begin{aligned}
& \text { Indeks keanekaragaman spesies } \\
& \mathrm{H}^{\prime}=-\Sigma(\mathrm{ni} / \mathrm{N} \ln \mathrm{ni} / \mathrm{N})
\end{aligned}
$$

Dimana: $\quad H^{\prime}=$ Indeks keanekaragaman spesies; ni = Jumlah individu dalam spesies ke-l; $\mathrm{N}=$ Jumlah total individu, dimana $H^{\prime}<1$ = Keanekaragaman rendah dan keadaan komunitas rendah;

$1<H^{\prime}<3=$ Keanekaragaman sedang dan keadaan sedang; $H^{\prime}>3=$ Keanekaragaman tinggi dan keadaan tinggi.

Indeks kekayaan jenis

$$
R_{1}=\frac{S-1}{\ln (N)}
$$

Dimana : $\mathrm{R}_{1}=$ Indeks kekayaan Margallef; $\mathrm{S}=$ Jumlah jenis; $\mathrm{N}=$ Total jumlah individu

\footnotetext{
Kepadatan (Cox 1967)

Kepadatan spes. =

$\mathrm{Jml}$ ind. per spesies

Luas area $\left(\mathrm{m}^{2}\right)$
} 
Kepadatan relatif $(\%)=$ Kepadatan spes. $\overline{\text { Kepadatan spesies total }}$

X 100

$>$ Frekuensi (Bengen 2000).

Frekuensi $(\mathrm{Fi})=\mathrm{Pi} / \sum \mathrm{P}$

Dimana : $\mathrm{Fi}=$ Frekuensi Jenis; $\mathrm{Pi}=$ Jumlah plot yang ditemukan jenis I; $\Sigma \mathrm{P} \quad=$ Jumlah semua plot

\section{Frekuensi relative $(\mathrm{Rfi})=\mathrm{Fi} / \sum \mathrm{F} \times 100$}

Dimana : $\mathrm{RFi}=$ Frekuensi relative; $\mathrm{Fi}=$ Frekuensi jenis I; $\Sigma F=$ Frekuensi semua jenis

$>\quad$ Indeks dominasi spesies (Odum 1996). Indeks dominasi $(\mathrm{C})=\Sigma(\mathrm{ni} / \mathrm{N})^{2}$

Dimana : $\quad C=$ Indeks dominan spesies; $\mathrm{ni}=$ Jumlah individu setiap spesies I; $N=$ Jumlah total individu seluruh spesies. Dimana $\mathrm{C}<0,50=$ Dominasi rendah; $0,50<\mathrm{C}<0,75=$ Dominasi sedang; $0,75<\mathrm{C}<1=$ Dominasi tinggi

\begin{tabular}{|c|c|}
\hline \multirow{3}{*}{$\begin{array}{l}\text { Dominansi } \\
\text { Relatif } \quad(\%)=\end{array}$} & $\begin{array}{l}\text { Dominasi } \\
\text { spesies A }\end{array}$ \\
\hline & \\
\hline & $\begin{array}{l}\text { Dominansi } \\
\text { total spesies }\end{array}$ \\
\hline
\end{tabular}

$>\quad$ Indeks nilai penting (Bengen 2000).

$$
I N P=R D i+R F i+R C i
$$

Dimana :

INP = Nilai penting jenis

$\mathrm{RDi} \quad=$ Kepadatan relatife jenis $\mathrm{i}$

$\mathrm{RFi} \quad=$ Frekuensi relatife jenis $\mathrm{i}$

$\mathrm{RCi}=$ Dominansi relatif jenis $\mathrm{i}$

\section{HASIL DAN PEMBAHASAN}

\section{Jenis-jenis Moluska}

Dari hasil penelitian yang dilakukan pada tiga stasiun penelitian di vegetasi mangrove Desa Kulu Kecamatan Wori Kabupaten Minahasa Utara, diperoleh 11 jenis moluska dari 8 famili (Tabel 1). Spesies-spesies yang dimaksud terdiri atas : Telescopium telescopium, Terebralia sulcata, Cerithidea cingulata, Nerita planospira, Nerita undata, Chicoreus capucinus, Littoraria scabra, Polymesoda expansa, Anomalocardia squamosa, Saccostrea cucculata, Isognomon ephippium.
Tabel 1. Spesies Moluska Yang Ditemukan di Setiap Stasiun Penelitian.

\begin{tabular}{|c|l|c|c|c|}
\hline No. & \multicolumn{1}{|c|}{ Spesies } & $\begin{array}{c}\text { Sta. } \\
\mathbf{1}\end{array}$ & $\begin{array}{c}\text { Sta. } \\
\mathbf{2}\end{array}$ & $\begin{array}{c}\text { Sta. } \\
\mathbf{3}\end{array}$ \\
\hline 1 & Littoraria scabra & $\checkmark$ & $\checkmark$ & $\checkmark$ \\
\hline 2 & Nerita planospira & $\checkmark$ & $\checkmark$ & $\checkmark$ \\
\hline 3 & Chicoreus capucinus & $\checkmark$ & $\checkmark$ & $\checkmark$ \\
\hline 4 & Nerita undata & $\checkmark$ & $\checkmark$ & $\checkmark$ \\
\hline 5 & Chrithidea cingulata & $\checkmark$ & $\checkmark$ & - \\
\hline 6 & Terebralia sulcata & $\checkmark$ & $\checkmark$ & $\checkmark$ \\
\hline 7 & $\begin{array}{l}\text { Telecopiun } \\
\text { telescopium }\end{array}$ & $\checkmark$ & - & $\checkmark$ \\
\hline 8 & $\begin{array}{l}\text { Polymesoda } \\
\text { expansa }\end{array}$ & - & - & $\checkmark$ \\
\hline 9 & $\begin{array}{l}\text { Isognomon } \\
\text { ephippium }\end{array}$ & $\checkmark$ & - & $\checkmark$ \\
\hline 10 & $\begin{array}{l}\text { Saccostrea } \\
\text { cucculata }\end{array}$ & $\checkmark$ & - & - \\
\hline 11 & $\begin{array}{l}\text { Anomalocardia } \\
\text { squamosa }\end{array}$ & - & $\checkmark$ & - \\
\hline
\end{tabular}

Keterangan: $(\checkmark)=$ Ada,$(-)=$ Tidak

Dari jenis-jenis yang didapat, ada 5 jenis yang umum ditemukan di tiga stasiun penelitian yakni, Nerita undata, Nerita planospira, Chicoreus capucinus, Littoraria scabra, Terebralia sulcata. Kemudian ada jenis-jenis yang ditemukan tidak di semua stasiun penelitian seperti Chrithidea cingulata dan Telecopiun telescopium yang ditemukan hanya 2 stasiun. Selanjutnya ada jenis yang hanya ditemukan pada satu stasiun yakni Polymesoda expansa, Isognomon ephippium, Saccostrea cucculata dan Anomalocardia squamosa. Moluska yang ditemukan merupakan penghuni asli vegetasi mangrove dan memiliki toleransi yang tinggi terhadap kondisi lingkungan.

\section{Keanekaragaman}

Hasil analisa untuk mendapatkan nilai indeks keanekaragaman spesies dari vegetasi mangrove ditunjukkan pada Gambar 2. Nilai indeks keanekaragaman moluska pada vegetasi mangrove di Desa Kulu adalah 2,060. Nilai indeks ini tergolong dalam kategori keanekaragaman sedang karena nilai $H^{\prime}$ lebih besar dari 1 dan lebih kecil dari 3 menurut kriteria Indeks ShanonWiener, keanekaragaman sedang kemungkinan disebabkan oleh faktor lingkungan dan predator yang relatif kecil mengakibatkan komunitas moluska yang tidak terlalu banyak. Sehingga dapat diartikan bahwa komunitas memiliki jumlah spesies yang tidak terlalu banyak. 


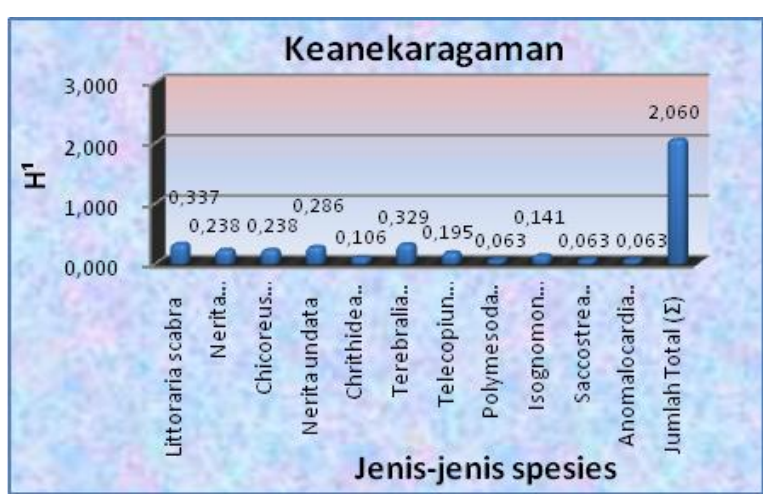

Gambar 2. Indeks Keanekaragaman Moluska di Vegetasi Mangrove DesaKulu Kecamatan Wori Kabupaten Minahasa Utara

Indeks Keanekaragaman spesies tertinggi yakni Littorari scabra dengan nilai indeks 0,337 dan terendah ada tiga spesies yang memiliki nilai indeks yang sama $(0,063)$ yakni Polymesoda expansa, Saccostrea cucculata dan Anomalocardia squamosa. Perbedaan keanekaragaman dapat disebabkan oleh distribusi dan jumlah spesies (Nybakken 1992).

\section{Kekayaan Spesies}

Nilai Indeks Kekayaan spesies moluska pada vegetasi mangrove di lokasi penelitian yakni 2,387 (Tabel 2). Nilai ideks kekayaan cenderung akan tinggi apabila suatu komunitas memiliki jumlah spesies yang banyak dan setiap spesies tersebut terwakili oleh satu individu, sebaliknya nilai indeks akan rendah jika suatu komunitas memiliki jumlah spesies yang cenderung sedikit dan setiap spesies tersebut memiliki jumlah individu yang banyak. Pada komunitas moluska di vegatasi mangrove Desa Kulu terdiri dari 66 individu yang tersebar pada 11 spesies.

Nilai indeks kekayaan merupakan efek dari komplesitas faktor lingkungan pada stasiun penelitian, misalnya berkaitan dengan keragaman substrat, salinitas, suhu, keberhasilan settlemen, pemangsaan serta faktor abiotik lainnya.
Tabel 2. Nilai Kekayaan Spesies

\begin{tabular}{|c|c|c|c|c|}
\hline \multicolumn{2}{|r|}{ Nama Spesies } & \multirow{2}{*}{$\begin{array}{c}\begin{array}{c}\text { St 1 } \\
\left(5 \mathrm{~m}^{2}\right)\end{array} \\
7\end{array}$} & \multirow{2}{*}{$\begin{array}{c}\begin{array}{c}\text { St } 2 \\
\left(5 m^{2}\right)\end{array} \\
3\end{array}$} & \multirow{2}{*}{ 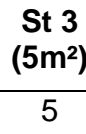 } \\
\hline 1 & Littoraria scabra & & & \\
\hline 2 & $\begin{array}{l}\text { Nerita } \\
\text { planospira }\end{array}$ & 3 & 3 & 1 \\
\hline 3 & $\begin{array}{l}\text { Chicoreus } \\
\text { capucinus }\end{array}$ & 4 & 2 & 1 \\
\hline 4 & Nerita undata & 2 & 2 & 6 \\
\hline 5 & $\begin{array}{l}\text { Chrithidea } \\
\text { cingulata }\end{array}$ & 1 & 1 & 0 \\
\hline 6 & $\begin{array}{l}\text { Terebralia } \\
\text { sulcata }\end{array}$ & 7 & 4 & 3 \\
\hline 7 & $\begin{array}{l}\text { Telecopiun } \\
\text { telescobium }\end{array}$ & 3 & 0 & 2 \\
\hline 8 & $\begin{array}{l}\text { Polymesoda } \\
\text { expansa }\end{array}$ & 0 & 0 & 1 \\
\hline 9 & $\begin{array}{l}\text { Isognomon } \\
\text { ephippium }\end{array}$ & 1 & 2 & 0 \\
\hline 10 & $\begin{array}{l}\text { Saccostrea } \\
\text { cucculata }\end{array}$ & 1 & 0 & 0 \\
\hline 11 & $\begin{array}{l}\text { Anomalocardia } \\
\text { squamosa }\end{array}$ & 0 & 1 & 0 \\
\hline & Jumlah $(\Sigma)$ & 29 & 18 & 19 \\
\hline
\end{tabular}

\section{Kepadatan dan Kepadatan Relatif}

Kepadatan moluska pada vegetasi mangrove di Desa Kulu Kecamatan Wori Kabupaten Minahasa Utara yakni 0,660 ind $/ \mathrm{m}^{2}$ (Gambar 3). Kepadatan spesies tertinggi yakni Littoraria scabra dengan nilai indeks $0,150 \mathrm{ind} / \mathrm{m}^{2}$ dengan kepadatan relatif $22,72 \%$ dan terendah yakni terdapat 3 spesies yaitu Polymesoda expansa, Saccostrea cucculata dan Anomalocardia squamosa dengan nilai indeks $0,010 \mathrm{ind} / \mathrm{m}^{2}$ dan kepadatan relatif $1,51 \%$.

Spesies yang memiliki kepadatan tergolong tinggi yakni Littoraria scabra yaitu $0,150 \mathrm{ind} / \mathrm{m}^{2}$ dengan kepadatan relatif $22,72 \%$. Dari hasil analisis menunjukan bahwa kepadatan spesies dan kepadatan relatif Littoraria scabra merupakan spesies yang memiliki kepadatan tertinggi. Tingginya kepadatan Littorari scabra pada penelitian ini menandakan bahwa Littoraria scabra yang mendiami daerah ini beradaptai dengan baik dan cocok hidup pada habitatnya. Menurut Odum (1998), suatu spesies yang mempunyai kepadatan tertinggi menunjukan bahwa organisme ini memiliki kemampuan menempati ruang yang lebih luas sehingga kesempatan untuk berkembang lebih banyak. 
Tingginya kepadatan relatif spesies Littorari scabra ini diduga memiliki adaptasi yang cukup besar dengan perubahan faktor lingkungan yang disebabkan oleh pasut air laut, suhu dan salinitas (Barnes dan Menn 1988). Spesies ini memiliki jumlah individu yang relatif lebih banyak dibandingkan dengan spesies lainnya yang ditemukan pada vegetasi mangrove di Desa Kulu.

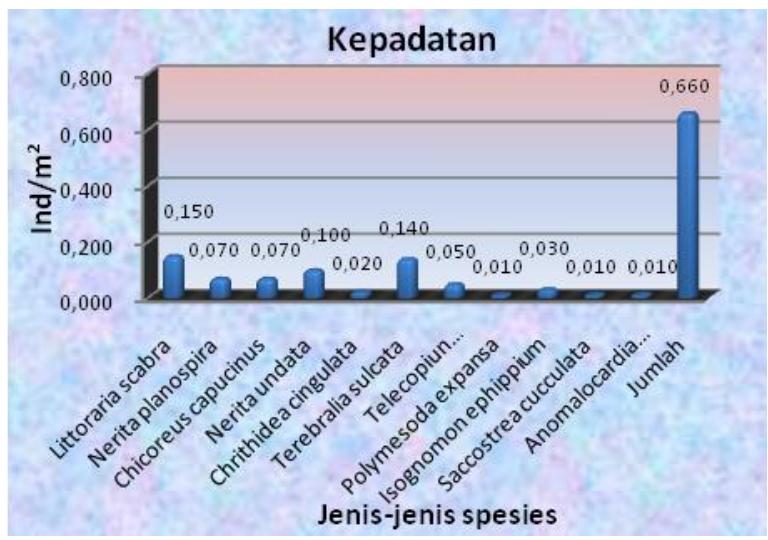

Gambar 3. Kepadatan Moluska pada Vegetasi Mangrove di Desa Kulu Kecamatan Wori Kabupaten Minahasa Utara.

\section{Frekuensi dan Frekuensi Relatif}

Nilai frekuensi kemunculan spesies pada vegetasi mangrove Desa Kulu Kecamatan Wori Kabupaten Minahasa Utara (Gambar 4). Nilai frekuensi kemunculan bervariasi antara 0,067 - 0,667. Spesies yang memiliki nilai frekuensi kemunculan tertinggi yakni Littoraria scabra 0,667 dengan nilai kemunculan relatifnya $18,86 \%$ dan Terebralia sulcata 0,667 dengan nilai kemunculan relatifnya $18,86 \%$ dan terendah pada Polymesoda expansa, Saccostrea cucculata dan Anomalocardia squamosa yang sama-sama memiliki nilai indeks 0,067 dan kemunculan relatif $1,88 \%$.

Littoraria scabra dan Terebralia sulcata memiliki nilai indeks kemunculan tertinggi dimana spesies ini hampir ditemukan pada semua plot/kuadran penelitian, dan juga kedua spesies ini memiliki jumlah individu yang relatif lebih bayak dibanding spesies yang lain.

Polymesoda expansa, Saccostrea cucculata dan Anomalocardia squamosa memiliki nilai frekuensi kemunculan terendah karena ketiga spesies ini hanya muncul pada satu plot penelitian dan juga spesies-spesies ini hanya diwakili masingmasing 1 individu.

\section{Dominasi dan Dominasi Relatif}

Nilai indeks dominasi moluska pada vegetasi mangrove di Desa Kulu Kecamatan Wori Kabupaten Minahasa Utara (Gambar 5). Nilai indeks dominasi pada lokasi penelian ini adalah 0,152 . Nilai dominasi spesies bervariasi antara 0,0002-0,0517. Pada lokasi penelitian ini spesies yang memiliki nilai indeks dominasi yang relatif tinggi yakni Littorari scabra 0,0517 dan dominasi relatif $34,09 \%$. Dominasi spesies terendah terdapat pada 3 spesies yakni Polymesoda expansa, Saccostrea cucculata dan Anomalocardia squamosa yakni samasama memiliki nilai 0,0002 dan dominasi relatif $0,15 \%$.

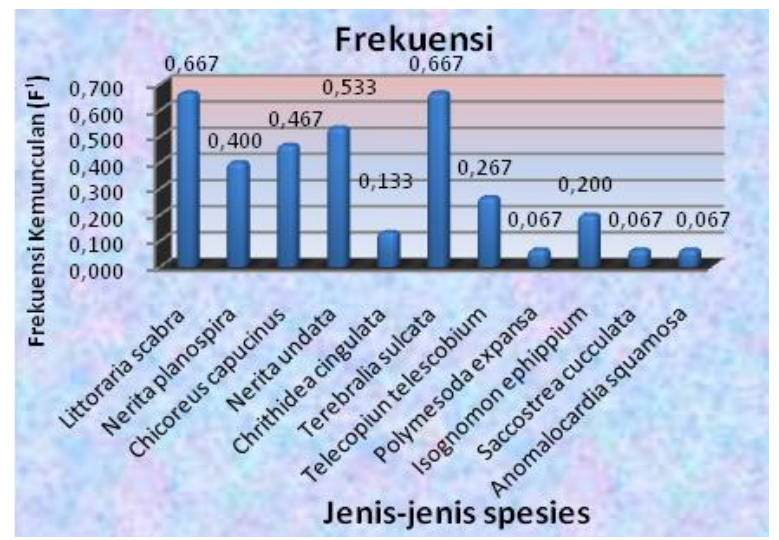

Gambar 4. Nilai Frekuensi Kemunculan Moluska pada Vegetasi Mangrove di Desa Kulu Kecamatan Wori Kabupaten Minahasa Utara.

Litoraria scabra memiliki nilai indeks dominasi tertinggi dimana spesies ini memiliki jumlah individu yang relatif lebih bayak dibanding spesies yang lain. Polymesoda expansa, Saccostrea cucculata dan Anomalocardia squamosa memiliki nilai dominasi terendah karena ketiga spesies ini memiliki jumlah individu yang paling sedikit dibanding spesies yang lain. Menurut (Mudjiono 2008) secara umum persentase kelas Gastropoda (keong) keberadaannya lebih tinggi dibandingkan kelas Bivalvia (kerang). Sehingga dapat diartikan pada lokasi penelitian didominasi organisme kecil. 


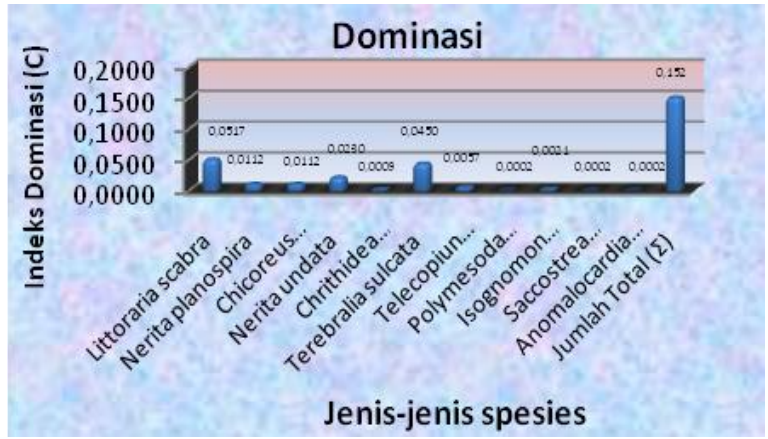

Gambar 5. Nilai Indeks Dominasi Moluska pada Vegetasi Mangrove di Desa Kulu Kecamatan Wori Kabupaten Minahasa Utara.

\section{Indeks Nilai Penting}

Indeks nilai penting yang diperoleh berdasarkan hasil analisis pada moluska di vegetasi mangrove Desa Kulu Kecamatan Wori Kabupaten Minahasa Utara seperti yang ditunjukan pada Gambar 6. Pada lokasi penelitian ini terdapat dua spesies yang memiliki indeks nilai penting relatif tinggi yakni Littoraria scabra $(75,67)$ dan Terebralia sulcata $(69,76)$ dimana dapat disimpulkan kedua spesies ini memiliki jumlah individu terbanyak dan terdapat di ke 3 stasiun penelitian. Nilai indeks terendah terdapat pada 3 spesies yakni Polymesoda expansa, Saccostrea cucculata dan Anomalocardia squamosa dengan nilai indeks 3,54, karena dari ke 3 spesies yang ditemukan hanya diwakili 1 individu dalam ke tiga stasiun penelitian.

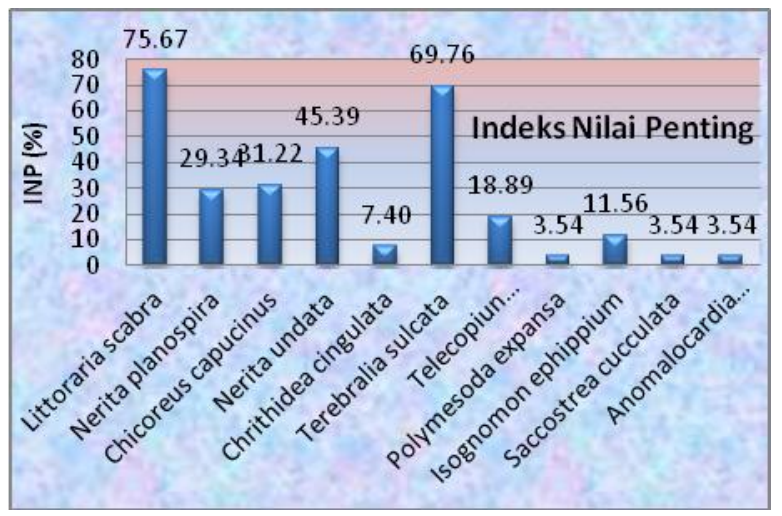

Gambar 6. Indeks Nilai Penting Moluska pada Vegetasi Mangrove di Desa Kulu Kecamatan Wori Kabupaten Minahasa Utara.

\section{KESIMPULAN}

Moluska yang ditemukan pada vegetasi mangrove di Desa Kulu Kecamatan
Wori Kabupaten Minahasa Utara sebanyak 11 spesies dari 8 famili yakni Telescopium telescopium, Terebralia sulcata, Cerithidea cingulata, Nerita planospira, Nerita undata, Chicoreus capucinus, Littoraria scabra, Polymesoda expansa, Anomalocardia squamosa, Saccostrea cucculata,dan Isognomon ephippium; mangrove yang diidentifikasi dari ketiga stasiun penelitian yaitu Rhizophora apiculata dan Rhizophora stylosa.

Keanekaragaman moluska dalam kategori keanekaragaman sedang. Nilai Indeks kekayaan moluska yaitu 2,387. Nilai kepadatan moluska pada vegetasi mangrove yaitu $0,660 \mathrm{ind} / \mathrm{m}^{2}$. Nilai frekuensi kemunculan tertinggi yakni Littoraria scabra, terendah pada Polymesoda expansa, Saccostrea cucculata dan Anomalocardia squamosa. Indeks dominasi moluska pada vegetasi mangrove yakni tergolong dalam dominasi rendah; artinya komunitas ini tidak terdapat spesies yang mendominasi secara signifikan. Indeks nilai penting relatif tinggi yakni Littoraria scabra dan terendah pada 3 spesies yaitu Polymesoda expansa, Saccostrea cucculata dan Anomalo cardia squamosa dengan nilai indeks.

\section{DAFTAR PUSTAKA}

Bakosurtanal. 1995. Peta Lingkungan Pantai Indonesia. Lembar LPI 217-04

Bengen, D.G. 2002. Pedoman Teknis Pengenalan dan Pengelolaan Ekosistem Mangrove. Pusat Kajian Sumberdaya Pesisir dan Lautan Institut Pertanian Bogor. Bogor, Indonesia.

Barnes, R.S.K dan K.H. Mann. 1988. Fundamentals of Aquatic Ecosystems. Blackwell Scientific Publications. London.

Cox, G.W. 1967. Laboratory Manual of General Ecology.W. M.c. Brown Company Publisher. USA. 165 hal.

Dharma, B. 1988. Siput Dan Kerang Indonesia (Indonesia Shells). Sarana Graha. Jakarta. 111 hal.

Dharma, B. 2005. Recent dan Fosil Indonesia Shell. PT. Ikrar Madiriabadi. Indonesia.

Mudjiono., M.M. Islami. 2009. Komunitas Moluska Di Perairan Teluk Ambon, 
Provinsi Maluku. UPT Balai Konservasi Biota Laut Ambon. LIPI.

Noor, Y.R., M. Khazali, I.N.N. Suryadiputra. 2006. Panduan Pengenalan Mangrove di Indonesia. PHKA/WI-IP, Bogor. $187 \mathrm{Hal}$.

Nybakken, J.W. 1992. Biologi Laut, Suatu Pendekatan Ekologi. PT, Gramedia. Jakarta.

Odum, E.P. 1998. Dasar-dasar ekologi. Terjemahan T. Samingan dan B. Srigdanono. Gajah Mada Press. Yogyakarta.

Odum, E.P. 1993. Dasar-dasar Ekologi. Edisi III. Universitas Gajah Mada, Yogyakarta.

Romimohtarto, K. dan S. Juwana. 2007. Biologi Laut. IImu pengetahuan tentang biota laut. Djambatan. 